\title{
A Study of Dynamic Loading and Unloading Damage of Fiber-Reinforced Concrete under Confining Pressure
}

\author{
Chao Lin $\mathbb{D}^{1},{ }^{1}$ Li Rao $\mathbb{D}^{1},{ }^{1}$ Cheng-Lin Zhang, ${ }^{1}$ Zhi-Wen Yang, ${ }^{1}$ Fang Chen, ${ }^{1}$ Qing You, \\ and Xian-Jun Tan ${ }^{2}$ \\ ${ }^{1}$ Physical Science and Technology College, Yichun University, Yichun 336000, Jiangxi, China \\ ${ }^{2}$ Institute of Rock and Soil Mechanics, Chinese Academy of Sciences, Wuhan, Hubei 430000, China \\ Correspondence should be addressed to Li Rao; raoli-ycu@hotmail.com
}

Received 10 November 2021; Revised 6 January 2022; Accepted 28 January 2022; Published 2 March 2022

Academic Editor: Xueming Du

Copyright (c) 2022 Chao Lin et al. This is an open access article distributed under the Creative Commons Attribution License, which permits unrestricted use, distribution, and reproduction in any medium, provided the original work is properly cited.

\begin{abstract}
Considering the influence of confining pressure in the actual service environment of concrete in underground projects, the damage characteristics of fiber-reinforced concrete under the action of confining pressure are evaluated according to the variation of measured permeability values by means of a triaxial ultralow permeability damage test system. The tests were carried out according to the stress loading and unloading paths of $1 \longrightarrow 5 \longrightarrow 10 \longrightarrow 15 \longrightarrow 20 \longrightarrow 10 \longrightarrow 5 \longrightarrow 1 \mathrm{MPa}$ for an axial pressure when the confining pressure value was $1 \mathrm{MPa}$ and kept constant. Firstly, the damage permeability of the fiber-reinforced concrete specimens was verified to be significantly lower than that of the ordinary concrete under the same confining pressure. Secondly, by conducting single loading and unloading tests at different loading rates $(0.5,1.0,1.5$, and $3.0 \mathrm{MPa} / \mathrm{s})$, it was confirmed that the loading rate had a significant effect on the damage cracking of the specimens, with the faster the loading rate, the more pronounced the damage characteristics. Finally, a triaxial cyclic dynamic load test with a confining pressure value of $1 \mathrm{MPa}$ and an axial loading speed of $1.5 \mathrm{MPa} / \mathrm{s}$ was carried out, revealing that the damage characteristics of the test blocks changed from elastic deformation to obvious plastic deformation damage as the number of loading times increased.
\end{abstract}

\section{Introduction}

As a new type of building material, fiber-reinforced concrete has good crack resistance and corresponding durability, enjoying a wide application prospect in the development of urban underground space [1]. During the actual service period, the fiber-reinforced concrete structure of urban underground engineering is in a complex stress environment, and the damage and cracking characteristics of the fiber-reinforced concrete structure under multiaxial stress conditions are different from those under uniaxial action mode. In actual working conditions, the fiber-reinforced concrete structure of urban underground engineering will be affected by certain confining pressure. Confining pressure has a certain synergistic effect on controlling plastic deformation of the fiber-reinforced concrete structure and improving elastic limit $[2,3]$. The fiber-reinforced concrete specimen is a typical strain rate-sensitive material. Under the condition of dynamic loading, the damage stress state of the fiber-reinforced concrete test blocks is no longer similar to the conventional quasi-static state. For example, under the conditions of high-speed loading and cyclic dynamic loading, the loading speed has a great influence on the degree of damage and cracking. Therefore, it is necessary to discuss the dynamic mechanical damage performance of fiberreinforced concrete materials [4-7].

In the study of dynamic damage mechanism of quasibrittle materials under confining pressure, Liu [8] studied the impact dynamic load mechanical properties of amphibolite under different confining pressure values $(0 \mathrm{MPa} \sim 2 \mathrm{MPa})$ and different strain rates. The results show that under the same confining pressure, with the increase of strain rate, the dynamic compressive strength of amphibolite shows a linear increase trend, which conforms to the strain rate correlation of strength, and the dynamic enhancement factor is approximately linear with the logarithm of strain rate. Within the same strain rate range, as the confining pressure increases, the strength enhancement effect becomes 
more obvious, showing a stronger confining pressure restraint effect. Lu and Wang [9] studied the loading damage test of biotite granite under the conditions of $0 \mathrm{MPa} \sim 3 \mathrm{MPa}$ confining pressure and medium and high strain rate. The test results show that when the confining pressure is constant, the dynamic compressive strength of granite increases logarithmically with the increase of strain rate, and the peak strain also increases with the increase of strain rate; the elastic modulus is poorly sensitive to confining pressure and strain rate, and the greater the strain rate, the more severe the rock fragmentation phenomenon under the premise of a constant strain rate, the dynamic compressive strength of granite rapidly increases with the increase of confining pressure, and the failure mode of the material changes from axial splitting under low confining pressure to compressionshear failure under high confining pressure; under high confining pressure, the stress-strain curve of granite has obvious brittle-ductile transition characteristics. Li [10] simulated the damage, deformation, strength evolution, and other failure characteristics of the circular roadway under the conventional triaxial constraint for three kinds of thickwalled cylindrical sandstone samples. Zhang [11] used the thick-walled cylindrical test block; after unloading the inner cavity load, continued to unload the outer cavity load of the undamaged thick-walled cylindrical limestone test block; and conducted a preliminary research on the unloading failure mode. $\mathrm{Wu}[10,12]$ carried out loading and unloading tests of limestone test blocks under different confining pressures, focusing on the failure mode of the samples under the condition of pressure relief in the hole, and revealed the damage failure mechanism.

Jia [13], based on the triaxial test of salt rock under multiple sets of confining pressures, used hyperbolic equations to fit the tensile and shear Mohr-Coulomb criteria to correct the sharp angle on the yield surface. The effects of the damage and confining pressure were added to the improved Mohr-Coulomb criterion, which can describe the mechanical characteristics of strain hardening, softening, and brittle-plastic transition of salt rock under different confining pressures. Zhou [14] obtained the quantitative relationship between elastic modulus and confining pressure and internal variables based on the cyclic loading test of Jinping marble. Based on the Mohr-Coulomb criterion, the law of internal friction angle and cohesion with internal variables is obtained. The internal friction angle in the yield function is replaced by the dilatancy angle to establish a plastic potential function. According to the noncorrelated flow rule, an elastoplastic coupled constitutive model of marble considering the confining pressure effect is given. The model can reflect the expansion characteristics of the rock with the change of confining pressure, but it uses many undetermined parameters, and because the research object is Jinping marble, the model is based on test results, and whether it is applicable to other rocks needs further verification. Wu and $\mathrm{Li}$ [15] produced a number of cylindrical concrete specimens and wrapped FRP cloth around the concrete specimens to limit the radial deformation during concrete loading. The deformation of concrete under multiaxial action was studied, and the reciprocating loading effect was obtained. Under the stress-strain curve, the confining pressure of the FRP sheet on concrete was studied.

In order to study the influence of confining pressure constraint and loading speed on the damage and cracking law of fiber-reinforced concrete, we carried out dynamic loading and unloading damage penetration tests of fiberreinforced concrete under confining pressure [16-21]. Under the condition of constant confining pressure of $1 \mathrm{MPa}$ and loading speed $(0.5,1.0,1.5$, and $2.0 \mathrm{MPa} / \mathrm{s})$, a triaxial loading mechanical damage test of test blocks was carried out to study the influence of loading speed change on the damage degree of test blocks. Furthermore, triaxial multiple cyclic loading tests with confining pressure of $1 \mathrm{MPa}$ and axial loading speed of $1.5 \mathrm{MPa} / \mathrm{s}$ were carried out to reveal the evolution law of damage penetration of test blocks with the increase of loading and unloading times.

\section{Principle of Ultralow Permeability Damage Test under Confining Pressure}

The appearance of internal cracks of fiber-reinforced concrete structures after loading damage will reduce impermeability. The permeability change rule obtained from triaxial loading stress measurement can more truly reflect the actual situation of internal loading damage and cracking of fiber-reinforced concrete [22-25]. Due to the quality of raw materials, construction operations, curing conditions, and other factors, it is difficult to avoid microcracks after pouring and molding. Except for surface cracks, microcracks in the concrete matrix are difficult to find and identify. Therefore, with the help of ultralow permeability damage testing system, the research on dynamic loading damage mechanism of fiber-reinforced concrete test blocks under confining pressure is conducted. The absolute permeability of that fiber-reinforced concrete specimen is obtained from the experiment, and the permeability measurement of the specimen is carried out based on Darcy's law, and the gas used is high purity nitrogen. The dynamic loading damage mechanism of test blocks under confining pressure is revealed through the laboratory nitrogen steady-state test evaluation.

For the calculation equation of nitrogen permeability in a stable state, it is to necessary take into account the influence of gas slip and inertial resistance, which is beneficial for the calculation equation to coincide with the actual situation of a gas stable state. In terms of the means of gas permeability measurement, nitrogen is used as the permeable medium of test block loading damage, and the following factors need to be considered: nitrogen is characterized by high compression. In a normal test environment, the relative density of a gas is relatively low. The influence of gravity factors can be ignored in the measured calculation of damage permeability. Nitrogen, under the pressure, enjoys fast flow speed at the crack position of the test block, and thus the slip speed of nitrogen needs to be considered.

Generally, the principle of nitrogen permeability calculation formula is based on the characteristics of homogeneity, isotropy, and temperature commonness of the internal medium of the test block. In actual working 
conditions, the material characteristics of the test block are difficult to meet the ideal requirements, and the test block is usually calculated as a cylinder. According to the corresponding relationship between the calculation direction of damage permeability and axial space, the actual calculation is mainly divided into two types: axial damage permeability is parallel to the axial direction of the test block based on the measured direction; Radial damage permeability can be defined as transverse damage permeability based on the measured direction, which is consistent with the crosssection of the test block.

The mathematical model for calculating the damage and permeability of steady-state test blocks loaded with nitrogen can be described as follows:

$$
k_{g}=\frac{2 \mu p_{r} q_{r}}{G_{f}\left(p_{1}-p_{2}\right)\left(p_{1}+p_{2}\right)},
$$

where $k_{g}$ is the measured value of permeability of the test block, $e-16 \mathrm{~m}^{2} ; p_{r}$ is the pressure under the measured environment, pa; $q_{r}$ is the measured nitrogen flow velocity per unit volume; $p_{1}$ is the pressure upstream of the test block inlet, pa; $p_{2}$ is the downstream pressure of the test block outlet, pa; and $G_{f}$ is a geometric revision factor.

$$
G_{f}=\frac{\pi r^{2}}{L},
$$

where $r$ is the radius of the test block, $m$ and $L$ is the length of the test block, $m$.

Brief description of nitrogen slip effect: In the actual measurement and calculation of low permeability materials, the slip effect of nitrogen is obvious, and Klinkenberg relation is usually used to correct the calculation of damage permeability as follows:

$$
\mathrm{k}_{g}=k_{s}\left(1+\frac{b}{p_{m}}\right)
$$

where $k_{s}$ is the inherent permeability of the medium inside the test block, $p_{m}$ is the average pressure of the test block, and $b$ is the uniform unit constant.

In the test, the upstream gas pressure is controlled by the pressure-reducing valve, and the downstream end is directly connected with the atmosphere. At the same time, the loading stress state of the test block is changed; the state information and flow rate information of the test block are collected and recorded; and the damage permeability of the fiber-reinforced concrete test block is calculated.

\section{Test Preparation}

3.1. Experimental Equipment. The experiment adopts a constant temperature ultralow permeability damage test system, and the accuracy can reach $1 e-23 \mathrm{~m}^{2}$. The whole set of equipment is accurate in control and collection with a high degree of automation and thus can realize accurate measurement of permeability of low permeability medium. The partition arrangement of the test system is shown in Figure 1. The whole system consists of a pressure control system, pipeline and clamper system, data acquisition, recording system, and so on. The pressure control system is composed of axial pressure, confining pressure control system, and air pressure control system. The axial and confining pressure are controlled by two ISCO pressure pumps, while the gas pressure is controlled by a gas pressure reducing valve connected with the gas cylinder. The pipeline system is also composed of two parts: one is a confining and axial pressure control pipeline (transmit confining pressure and axial pressure) and the other is a gas migration pipeline (transport high purity gas used for infiltration). The clamper system consists of a rubber sleeve, a containing cavity, a cushion block, and the like, wherein the cylindrical sample is placed in the rubber sleeve, the cushion block is placed into the clamping sample from the upper and lower ends, and then the rubber jacket is placed in the containing cavity; The data acquisition and recording system consists of an electronic balance that automatically records reading books and a control system of a computer terminal. This system records various data in the test.

The steady-state method was adopted for the test block loading gas permeability test, and the permeability gas was high purity nitrogen. The gas permeability test not only studied the influence of fiber addition on the permeability of fiber-reinforced concrete but also studied the influence law of axial stress on the permeability of fiber-reinforced concrete test block. Considering the actual working conditions, infrastructure projects with shallow burial depth and low confining pressure are adopted for the development of urban underground space. The actual confining pressure of $1 \sim 2 \mathrm{MPa}$ is reasonable for the site selection environment. During the test, the test block was put into the clamping system first, and the pipeline connection was normal, so as to maintain the tightness of the clamping chamber and prevent the leakage of pressure liquid. The pressure load was slowly applied to the test block in the form of step loading; the confining pressure pump kept the set pressure unchanged; and the axial pressure is set to step loading and unloading mode. According to the influence law of triaxial loading on the damage permeability of the test block, the loading stress path shall be $1 \longrightarrow 5 \longrightarrow 10 \longrightarrow 15 \longrightarrow 20 \longrightarrow 10 \longrightarrow 5 \longrightarrow 1 \mathrm{MPa}$. The gas pressure at the upstream of the test block was $0.5 \mathrm{MPa}$, and we recorded the volume of permeated gas at the downstream by drainage method and converted the mass of discharged boiled water into the gas volume by electronic balance. The computer terminal automatically collected the data of the electronic balance and processed it into flow data for storage.

3.2. Preparation of Test Block. We cured the fiber-reinforced concrete standard cube test block that has been poured and cured to 28 days old. Then, the test block was made into a cylindrical test block with a diameter of $50 \mathrm{~mm}$ and a height of $40 \mathrm{~mm}$ (error control within $\pm 1 \mathrm{~mm}$ ) through drilling core and surface polishing. The test block parameters are shown in Table 1. Parallel control tests are required for fiber-reinforced concrete test blocks with the same content. The physical picture of the test blocks used in the damage penetration test is shown in Figure 2(a), and the schematic diagram of the loading direction of the test block is shown in Figure 2(b). 


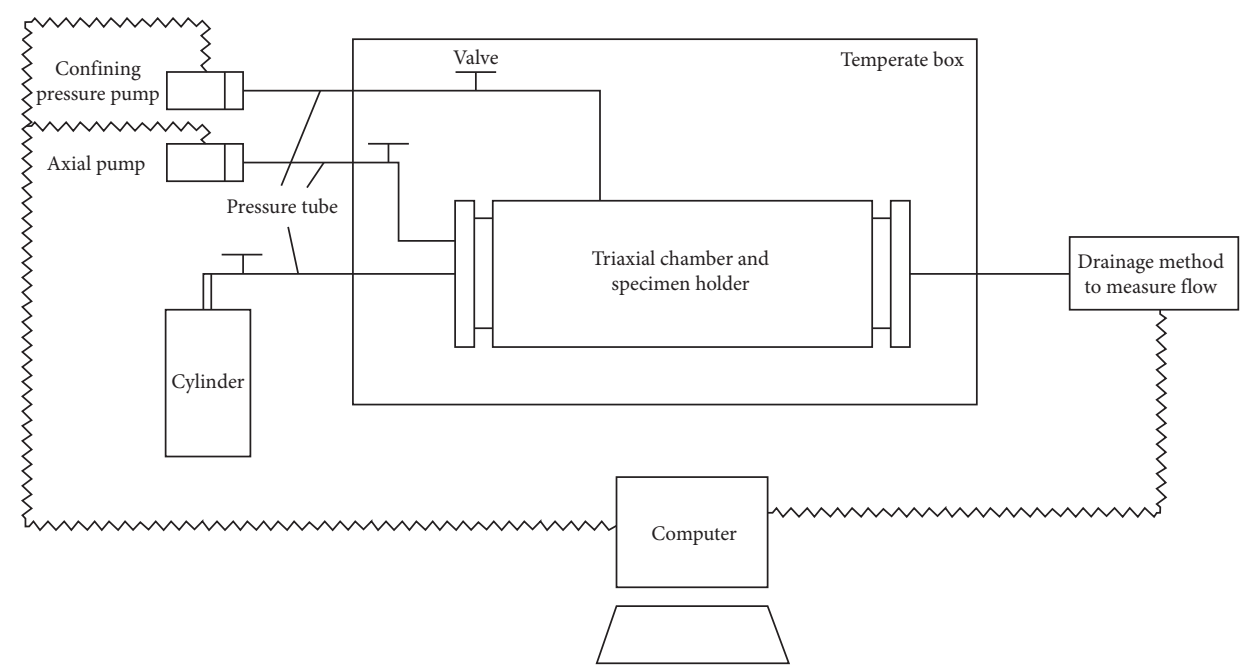

(a)
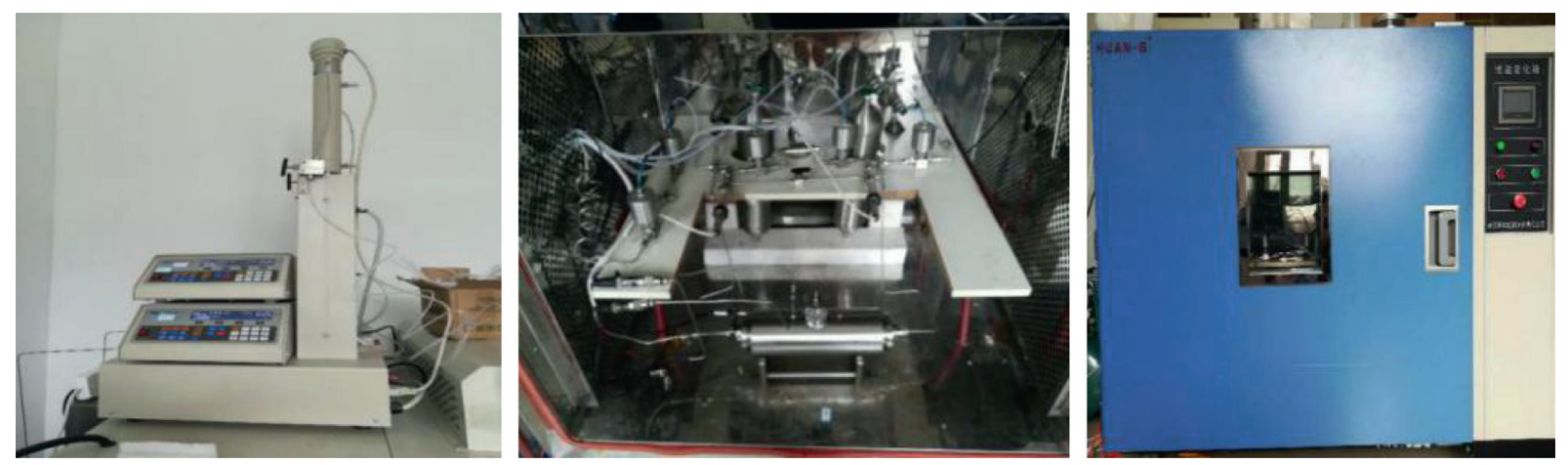

(b)

FIgure 1: Ultralow permeability damage test system: (a) schematic diagram and (b) physical picture.

TABLE 1: Test block parameters of damage penetration loading test under confining pressure.

\begin{tabular}{lccccc}
\hline Number & Strength level & Test blocks number $(n)$ & Fiber content $\left(\mathrm{kg} / \mathrm{m}^{3}\right)$ & \multicolumn{2}{c}{ Test block size } \\
& & & & Diameter $(\mathrm{mm})$ & Height $(\mathrm{mm})$ \\
\hline C50S1.2-1 & C50 & 16 & 1.2 & 50 & 40 \\
C50S1.2-2 & C50 & 16 & 1.2 & 50 & 40 \\
C50S0-1 & C50 & 16 & 0 & 50 & 30 \\
C50S0-2 & C50 & 16 & 0 & 50 \\
\hline
\end{tabular}

In order to improve the measurement accuracy of dynamic loading damage permeability of fiber-reinforced concrete test blocks under confining pressure, it is necessary to place the prepared concrete test blocks in an oven at $60^{\circ} \mathrm{C}$ for $12 \mathrm{~h}$, remove free moisture in the test blocks, let them cool down naturally, and store them in plastic sealed bags for subsequent tests.

\section{Study of Loading and Unloading Damage Penetration of Test Blocks under Confining Pressure}

4.1. Study of Damage and Penetration of Test Blocks under Static Loading and Unloading. According to the GB500812002 Test Method for Mechanical Properties of Concrete, when the strength grade of concrete is between C30 and C60, the static loading speed should be controlled at $0.5 \sim 0.8 \mathrm{MPa} / \mathrm{s}$. This section focuses on the evaluation of damage characteristics of test blocks under static confining pressure, and the loading speed is controlled at $0.5 \mathrm{MPa} / \mathrm{s}$. We carried out the load damage permeability test of the test block when the confining pressure value is $1 \mathrm{MPa}$ with C50S1.2 fiber-reinforced concrete test block and C50S0 ordinary concrete test block (the measured number of test blocks in each group is 2), and the loading speed was $0.5 \mathrm{MPa} / \mathrm{s}$. The measured data are shown in Table 2 . The measured data curve of the damage permeability test of fiber-reinforced concrete test block under the condition of single loading and unloading is shown in Figure 3.

As can be seen from Figure 3, both the fiber-reinforced concrete test block and the ordinary concrete test block show that the permeability increases with the increase of axial 


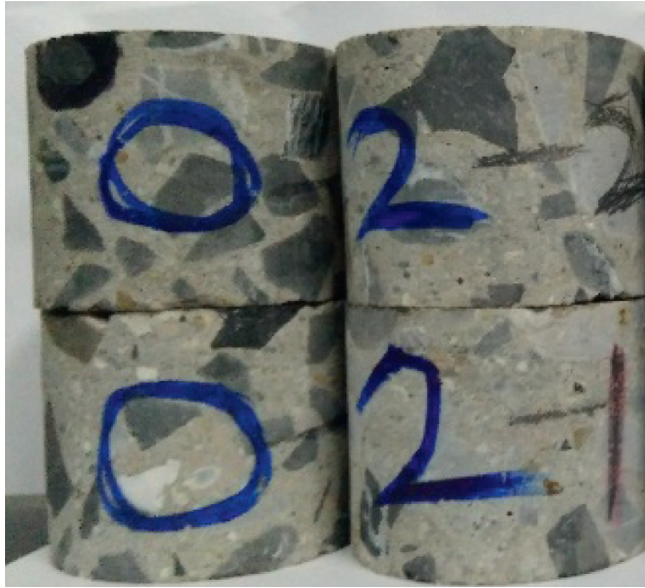

(a)

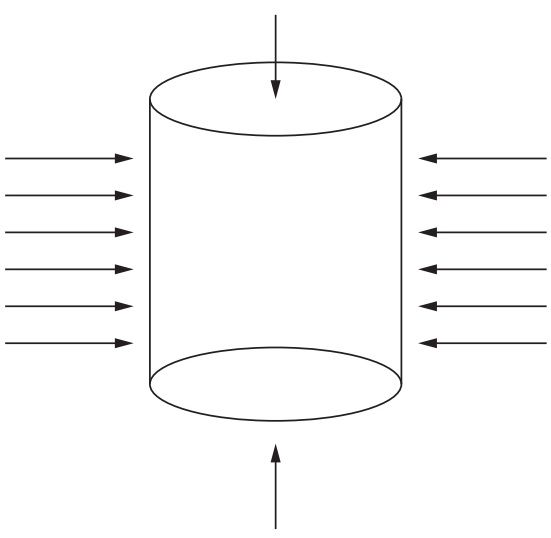

(b)

Figure 2: (a) Physical picture of the test blocks in the damage permeation loading test and (b) schematic diagram of confining pressure and axial loading of the test block.

TABLE 2: Measured permeability of single loading and unloading test (the confining pressure value is $1 \mathrm{MPa}$ ).

\begin{tabular}{|c|c|c|c|c|}
\hline \multirow{2}{*}{ Axial Load (MPa) } & C50S1.2-1 & C50S1.2-2 & C50S0-1 & C50S0-2 \\
\hline & \multicolumn{4}{|c|}{ Measured value of permeability $\left(e-16 \mathrm{~m}^{2}\right)$} \\
\hline 1 & 2.65 & 2.37 & 2.66 & 2.54 \\
\hline 5 & 3.12 & 2.60 & 3.05 & 2.86 \\
\hline 10 & 3.41 & 5.54 & 6.76 & 7.39 \\
\hline 15 & 5.68 & 6.97 & 11.20 & 12.45 \\
\hline 20 & 7.95 & 7.77 & 13.35 & 14.67 \\
\hline 10 & 4.92 & 4.64 & 8.96 & 6.82 \\
\hline 5 & 3.86 & 3.38 & 4.32 & 4.40 \\
\hline 1 & 3.62 & 3.52 & 4.08 & 4.15 \\
\hline
\end{tabular}

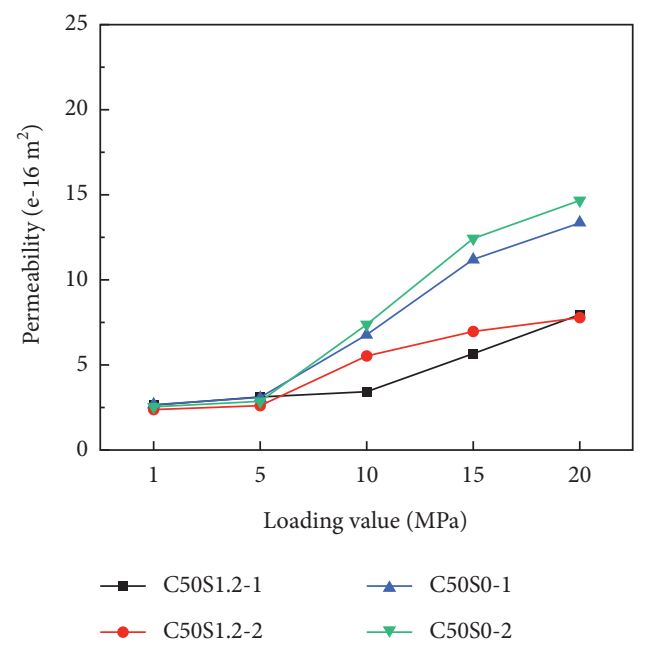

(a)

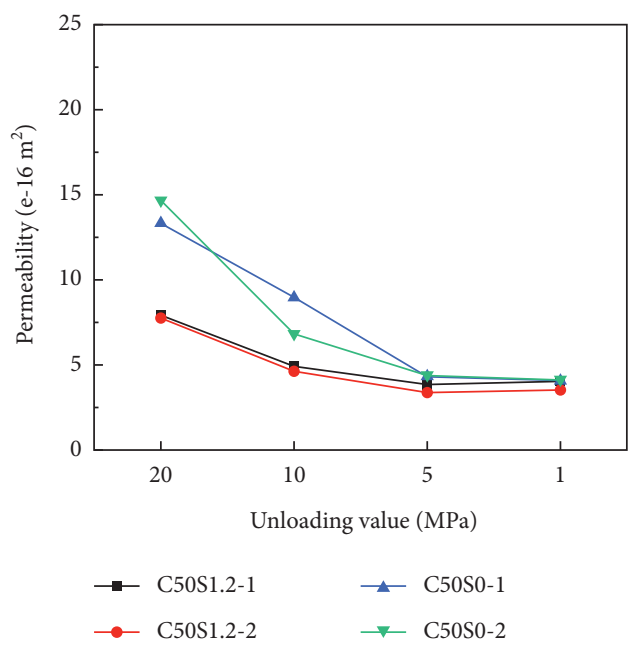

(b)

FIGURE 3: Change of loading and unloading damage permeability law of confining pressure 1 MPa test block: (a) load phase and (b) unload phase.

loading pressure. When the axial loading is $1 \sim 5 \mathrm{MPa}$, the permeability of the test block increases slowly, and when the axial loading is $5 \sim 15 \mathrm{MPa}$, the permeability increases rapidly.
When the loading peak value of the fiber-reinforced concrete test block reaches $20 \mathrm{MPa}$, the permeability peak value is $7.95 e-16 \mathrm{~m}^{2}$, and the permeability peak value of the 
ordinary concrete test block is $14.67 e-16 \mathrm{~m}^{2}$, which indicates that the cracking damage degree of the ordinary concrete test block under loading is greater than that of the fiber-reinforced concrete test block. The unloading speed is still kept at $0.5 \mathrm{MPa} / \mathrm{s}$. From the data curve, it can be seen that when the permeability of the test block is unloaded from the peak value to the initial loading value, the permeability basically decreases to that of the initial state, and the loading damage of the test block is mainly manifested as elastic deformation. However, the test block still causes slight cracking damage after single loading and unloading, which leads to the inability to completely restore the permeability to the initial level. The permeability of the fiber-reinforced concrete test block after unloading is $3.62 e-16 \mathrm{~m}^{2}$, which is slightly lower than the permeability of the ordinary concrete after unloading $4.08 e-16 \mathrm{~m}^{2}$, indicating that the damage and cracking degree of the fiber-reinforced concrete is lower than that of the ordinary concrete under the same loading and unloading conditions.

\subsection{Damage and Permeability Evaluation of Test Block under} Single Loading and Unloading under Different Loading Velocity. Considering the constant confining pressure value of $1 \mathrm{MPa}$ and the change of loading speed $(0.5,1.0,1.5$, and $3.0 \mathrm{MPa} / \mathrm{s}$ ), we carried out single loading and unloading damage permeability test of fiber-reinforced concrete test blocks with a strength grade of C50. The measured values of loading permeability of test blocks are shown in Table 3 . The loading and unloading damage penetration of the test block is shown in Figure 4.

According to the damage permeability curve of fiberreinforced concrete test blocks under different loading speeds, the following conclusions are obtained:

(1) The loading speed has a great influence on the damage permeability of the test block. When the loading speed is $0.5 \mathrm{MPa} / \mathrm{s}$, the confining pressure is $1 \mathrm{MPa}$, and the axial loading is $20 \mathrm{MPa}$, the peak damage permeability of the test block is $5.45 e-16 \mathrm{~m}^{2}$, and when the loading speed is increased to $1.0 \mathrm{MPa} / \mathrm{s}$, the peak damage permeability of the test block is $7.77 e-16 \mathrm{~m}^{2}$. The degree of damage and cracking is further increased. When the loading speed is increased to $1.5 \mathrm{MPa} / \mathrm{s}$, the peak damage permeability of the test block is $28.35 e-16 \mathrm{~m}^{2}$. When the loading speed is increased to $3 \mathrm{MPa} / \mathrm{s}$, the peak damage permeability of the test block is sharply increased to $122.37 e-16 \mathrm{~m}^{2}$, and the test block has an obvious cracking failure.

(2) Through the comparison and analysis of the measured values of the damage permeability of the test block, it can be seen that when the loading rate is $0.5 \sim 1.0 \mathrm{MPa} / \mathrm{s}$, the permeability of the test block basically recovers to the initial value after a single loading and unloading test, which indicates that the damage deformation of the test block is mainly manifested as elastic damage at this stage. When the loading speed is increased to $1.5 \mathrm{MPa} / \mathrm{s}$, the permeability of the test block after unloading is $8.17 e-16 \mathrm{~m}^{2}$, which is obviously higher than the initial value of $2.66 e-16 \mathrm{~m}^{2}$, indicating that the test block has plastic damage. When the loading rate is increased to $3 \mathrm{MPa} / \mathrm{s}$, the permeability of the test block after unloading is $39.37 e-16 \mathrm{~m}^{2}$, which is much higher than the initial value of $2.74 e-16 \mathrm{~m}^{2}$, indicating that the test block has obvious plastic damage.

4.3. Evaluation of Damage and Permeability of Test Blocks under Rapid Cyclic Loading and Unloading. Under conventional test conditions, the loading speed of fiber-reinforced concrete test block is generally controlled at $0.5 \sim 0.8 \mathrm{MPa} / \mathrm{s}$. This section mainly studies the damage characteristics of fiber-reinforced concrete test block under dynamic load and cyclic loading and unloading. It can be seen from the research results of the previous section that the loading speed has a great influence on the damage of the test block. Therefore, this section focuses on the damage penetration test of C50S0 ordinary concrete and C50S1.2 fiberreinforced concrete under fast cyclic loading and unloading. The confining pressure is kept constant at $1 \mathrm{MPa}$, and the loading speed is increased to $1.5 \mathrm{MPa} / \mathrm{s}$. Four cyclic loading and unloading tests were carried out in turn through the same stress loading and unloading path. When the fourth cyclic axial pressure is unloaded to $1 \mathrm{MPa}$, the data are recorded and analyzed at the end of the test. The loading and unloading path of the test stress is shown in Figure 5. Under cyclic dynamic load conditions, the measured values of loading permeability of fiber-reinforced concrete test blocks are shown in Tables 4 and 5, and the loading and unloading damage permeability of test blocks are shown in Figures 6 and 7.

The research shows that the permeability of the test block increases with the increase of axial compression loading in the loading stage, mainly showing that with the increase of axial compression, the crack expansion of the test block leads to the increase of the measured permeability value. At the beginning of the loading stage, the slope of the curve of permeability changing with axial pressure is relatively moderate, and with the increase of axial pressure, the slope of the curve of permeability changing with axial pressure gradually becomes steeper. In the unloading stage, the permeability decreases with the decrease of axial pressure, which is mainly manifested as the fracture tends to close due to axial pressure unloading. In the initial stage of unloading, the slope of the curve of permeability with axial pressure is larger and continues to decrease with axial pressure, while the slope of the curve of permeability with axial pressure gradually slows down. The research shows that the loading stage (10 15 MPa) is the critical stage of damage infiltration of test blocks, which can be defined as the transition stage of elastoplastic damage infiltration.

At the peak loading stages of four cycles, the permeability of fiber-reinforced concrete test block is $28,31,35$, and $39 e-16 \mathrm{~m}^{2}$, respectively, and when the axial load is unloaded to $1 \mathrm{MPa}$, the permeability of fiber-reinforced 
TABLE 3: Measured permeability of C50S1.2 test block in dynamic loading and unloading test (the confining pressure value is $1 \mathrm{MPa}$ ).

\begin{tabular}{lcccc}
\hline Axial Load (MPa) & Loading speed, $0.5 \mathrm{MPa} / \mathrm{s}$ & $\begin{array}{c}\text { Loading speed, } 1.0 \mathrm{MPa} / \mathrm{s} \\
\text { Measured value of permeability }\left(e-16 \mathrm{~m}^{2}\right)\end{array}$ & $\begin{array}{c}\text { Loading speed, } 1.5 \mathrm{MPa} / \mathrm{s} \\
\text { Loading speed, } 3.0 \mathrm{MPa} / \mathrm{s}\end{array}$ \\
\hline 1 & 2.55 & 2.68 & 2.66 & 7.15 \\
5 & 3.46 & 3.60 & 11.34 & 2.74 \\
10 & 3.55 & 4.54 & 21.48 & 29.35 \\
15 & 3.68 & 5.87 & 28.35 & 76.34 \\
20 & 5.45 & 7.77 & 17.68 & 122.37 \\
10 & 4.34 & 5.24 & 10.24 & 56.54 \\
5 & 3.77 & 4.28 & 8.17 & 43.56 \\
1 & 3.34 & 3.77 & & 39.75 \\
\hline
\end{tabular}

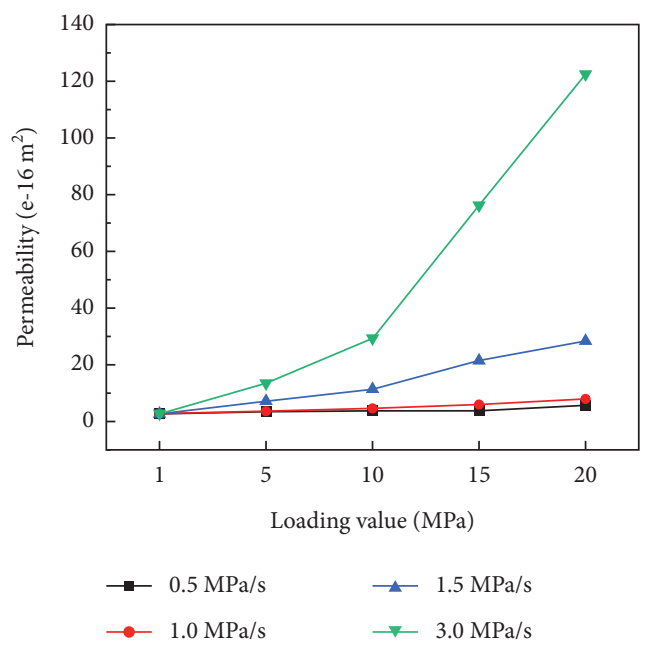

(a)

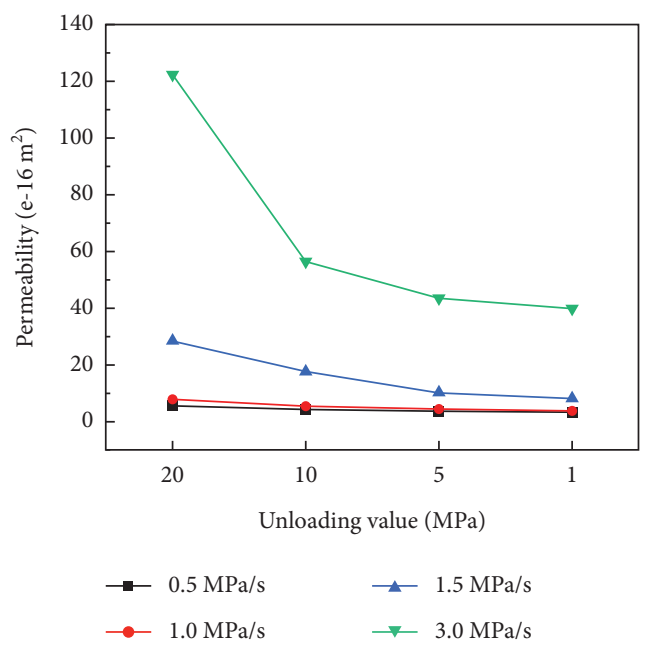

(b)

FIGURE 4: Change of damage penetration law of C50S1.2 test block in dynamic loading and unloading test: (a) load phase and (b) unload phase.

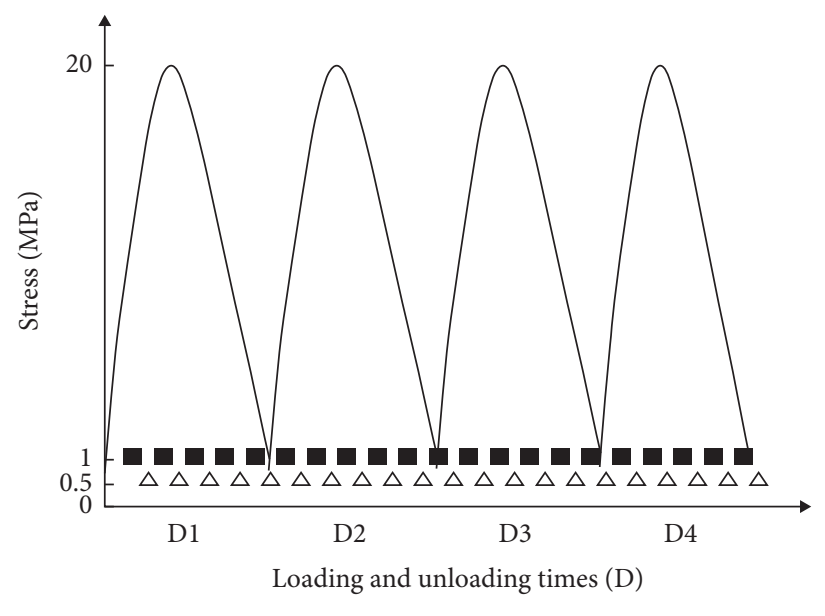

- Confining pressure constant load

$\Delta \quad$ Nitrogen pressure

- Axial load

FIgURE 5: Cyclic loading and unloading path of test block. 
TABLE 4: Measured permeability of C50S1.2-1 test block in cyclic loading and unloading test.

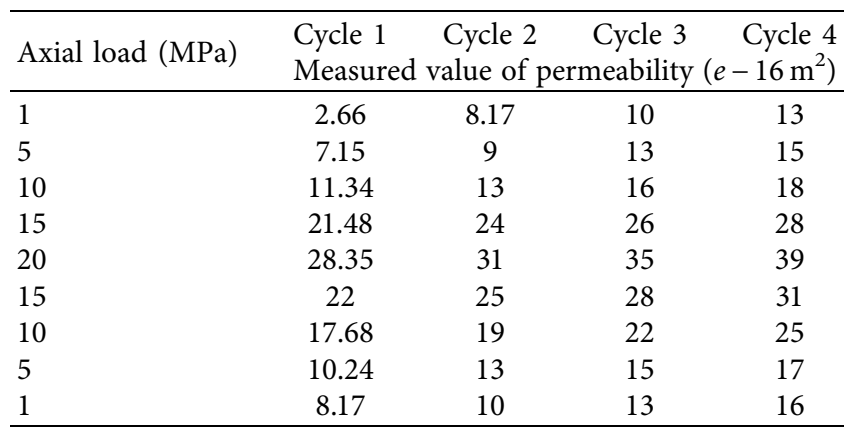

TABLE 5: Measured permeability of C50S1.2-2 test block in cyclic loading and unloading test.

\begin{tabular}{|c|c|c|c|c|}
\hline \multirow{2}{*}{ Axial load (MPa) } & Cycle 1 & Cycle 2 & Cycle 3 & Cycle 4 \\
\hline & \multicolumn{4}{|c|}{ Measured value of permeability $\left(e-16 \mathrm{~m}^{2}\right)$} \\
\hline 1 & 2.39 & 7.14 & 11 & 12 \\
\hline 5 & 6.15 & 10 & 12 & 15 \\
\hline 10 & 12.37 & 14 & 17 & 19 \\
\hline 15 & 20.45 & 23 & 26 & 27 \\
\hline 20 & 27.37 & 30 & 34 & 38 \\
\hline 15 & 21 & 23 & 29 & 30 \\
\hline 10 & 16.66 & 17 & 21 & 24 \\
\hline 5 & 9.25 & 14 & 15 & 18 \\
\hline 1 & 7.14 & 11 & 12 & 17 \\
\hline
\end{tabular}

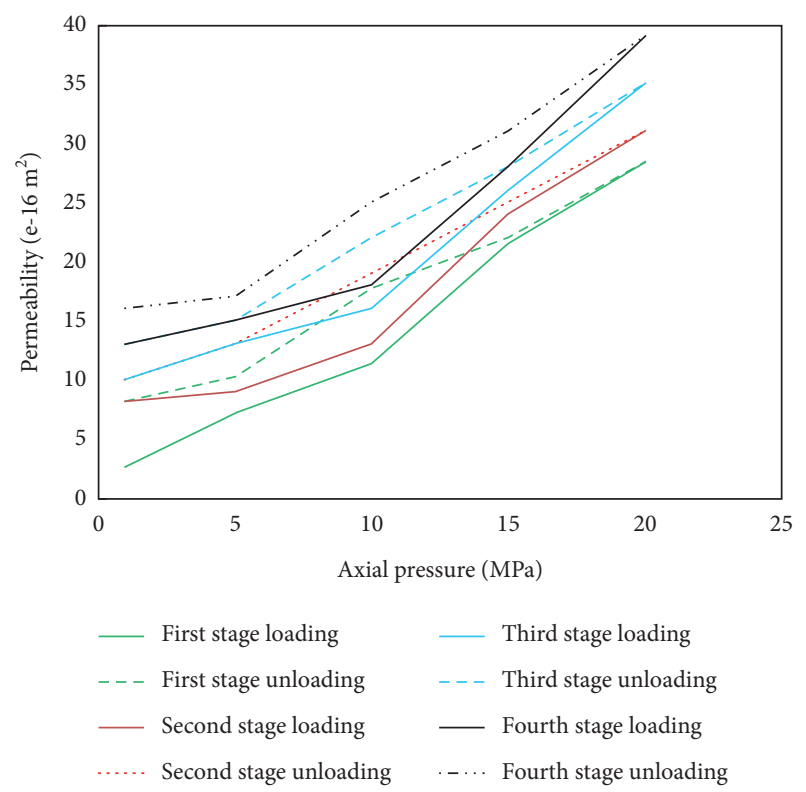

FIGURE 6: Change of damage penetration law of C50S1.2-1 test block in cyclic loading and unloading test.

concrete test block corresponding to the four cycles is 8,10 , 13 , and $16 e-16 \mathrm{~m}^{2}$, respectively. It can be seen that the damage permeability of the test block increases with the increase of loading and unloading times. Under the action of cyclic loading and unloading, the damage degree of the test block increases, and the permeability of each stage is higher
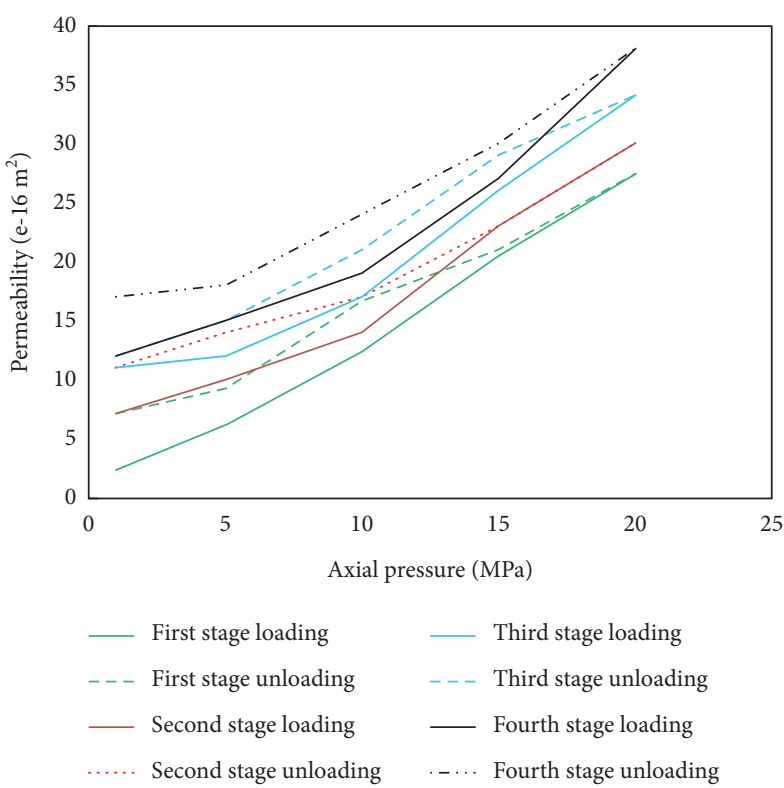

FIgURE 7: Change of damage penetration law of C50S1.2-2 test block in cyclic loading and unloading test.

than that of the previous stage. The test block has obvious plastic deformation damage, which is mainly manifested in the fact that the crack permeability after unloading is significantly higher than the initial permeability after loading.

\section{Conclusions}

Considering the presence of confining pressure in engineering practice, a study on the dynamic loading damage mechanism of fiber-reinforced concrete specimens under confining pressure was carried out with the aid of an ultralow permeability damage test system, and the following conclusions were mainly obtained:

(1) The damage characteristics of fiber-reinforced concrete and ordinary concrete specimens in a single loading and unloading under the same confining pressure were studied, which shows that under the same confining pressure and loading and unloading conditions, the damage permeability of the fiberreinforced concrete specimens is significantly lower than that of the ordinary concrete. The penetration rate in the unloading phase of the test basically overlaps with that in the loading phase, which is mainly characterized by elastic damage.

(2) Considering that the loading speed is an important factor affecting the damage cracking of fiber-reinforced concrete, damage penetration tests were carried out on the triaxial single loading and unloading of fiber-reinforced concrete specimens under the conditions of varying loading speeds $(0.5$, $1.0,1.5$, and $3.0 \mathrm{MPa} / \mathrm{s}$ ) with a constant confining pressure of $1 \mathrm{MPa}$. The study shows that the loading speed has a great influence on the degree of damage and cracking of the specimen. When the loading speed is increased from $0.5 \mathrm{MPa} / \mathrm{s}$ to $1.5 \mathrm{MPa} / \mathrm{s}$, the 
maximum permeability at the peak of loading increases from $5.45 e-16 \mathrm{~m}^{2}$ to $28.35 e-16 \mathrm{~m}^{2}$, and the rapid increase of permeability indicates that the degree of damage and cracking of the specimen becomes larger. When the loading speed reached $3 \mathrm{MPa} / \mathrm{s}$, the permeability of the unloading phase could not coincide with that of the loading phase, and the permeability of the specimen at the end of unloading was $39.37 e-16 \mathrm{~m}^{2}$ that was significantly higher than the initial measured value of $2.74 e-16 \mathrm{~m}^{2}$.

(3) A triaxial cyclic loading and unloading test was carried out at a circumferential pressure of $1 \mathrm{MPa}$ and a loading rate of $1.5 \mathrm{MPa} / \mathrm{s}$. A total of four cycles of loading and unloading tests were carried out using the same loading path. The study shows that the damage penetration of the test blocks increases with the number of loading and unloading cycles.

\section{Data Availability}

The data used to support the findings of this study are available from the corresponding author upon request.

\section{Conflicts of Interest}

The authors declare that there are no conflicts of interest.

\section{Authors' Contributions}

C.L. conceptualized the study; L.R., Q.Y., and F.C. performed the experiment; Z.-W.Y. and X.-J.T. performed the analysis; C.L., L.R., and Q.Y. wrote the manuscript; and C.L. contributed to the funding acquisition. All authors have read and agreed to the final version of the manuscript.

\section{Acknowledgments}

The authors kindly thank the laboratory and experimental equipment provided by the Institute of Rock and Soil Mechanics, Chinese Academy of Sciences. This research was funded by the National Natural Science Foundation of China (Grant No. 51379200) and also by the Project of Science and Technology from the Department of Education in Jiangxi, China (GJJ190835).

\section{References}

[1] Y. Guan, D. Niu, B. Wu, and J. Wang, "Research on meso stochastic damage constitutive model of fiber concrete under compression," Journal of Xi'an University of Architecture and Technology (Natural Science Edition), vol. 47, no. 5, pp. 678-683, 2015.

[2] G. Walton, A. Hedayat, E. Kim, and D. Labrie, "Post-yield strength and dilatancy evolution across the brittle-ductile transition in Indiana limestone," Rock Mechanics and Rock Engineering, vol. 50, no. 4, pp. 1-20, 2017.

[3] G. Aráoz and B. Luccioni, "Modeling concrete like materials under sever dynamic pressures," International Journal of Impact Engineering, vol. 76, pp. 139-154, 2015.
[4] Z. Li and Z. Liu, "Review of concrete dynamic constitutive models," Journal of Tianjin University: Natural Science and Engineering Technology Edition, vol. 48, no. 10, pp. 853-863, 2015.

[5] A. Gholampour, T. Ozbakkaloglu, and R. Hassanli, "Behavior of rubberized concrete under active confinement," Construction and Building Materials, vol. 138, pp. 372-382, 2017.

[6] F. Gong, Si Xuefeng, X. Li, and M. Tao, "Research on dynamic Mohr-Coulomb criterion and Hoek-Brown criterion based on strain rate effect," Chinese Journal of Nonferrous Metals, vol. 26, no. 8, pp. 1763-1773, 2016.

[7] D. Unteregger, B. Fuchs, and G. Hofstetter, "A damage plasticity model for different types of intact rock," International Journal of Rock Mechanics and Mining Sciences, vol. 80, pp. 402-411, 2015.

[8] J. Li, J. Xu, X. Lu, Z. Wang, and L. Zhang, "Study on dynamic behavior and damage constitutive model of rock under impact loading with confining pressure," Engineering Mechanics, vol. 29, no. 1, pp. 55-63, 2012.

[9] Z. Lu and Z. Wang, "Triaxial test study on dynamic characteristics of granite considering medium and high strain rates," Chinese Journal of Geotechnical Engineering, vol. 38, no. 6, pp. 1087-1094, 2016.

[10] X. Li, Q. Wu, L. Dong, and L. Chen, "Research on the mechanical properties of thick-walled cylindrical sandstone with filling," Chinese Journal of Geotechnical Engineering, vol. 37, no. 12, pp. 2149-2156, 2015.

[11] H. Zhang, H. Liu, Y. He, and L. J. Han, "Unloading test and rock strength failure of rock thick-walled cylinder under threedimensional compression," Journal of University of Science and Technology Beijing, vol. 33, no. 7, pp. 800-805, 2011.

[12] C. Su, B. Li, and Q. Wu, "Experimental study on deformation and strength characteristics of limestone pore samples under compression," Chinese Journal of Rock Mechanics and Engineering, vol. 35, pp. 2739-2748, 2016.

[13] S. Jia, J. Luo, J. Yang, and M. Gao, "Research on elastoplastic damage constitutive model of salt rock considering the effect of confining pressure," Rock and Soil Mechanics, vol. 36, no. 4, pp. 1549-1556, 2015.

[14] H. Zhou, F. Yang, C. Zhang, and R. Xu, "Research on elastoplastic coupling mechanical model of marble considering confining pressure effect," Chinese Journal of Rock Mechanics and Engineering, vol. 31, no. 12, pp. 2389-2399, 2012.

[15] Y. F. Wu and P. Li, "Stress-strain behavior of actively and passively confined concrete under cyclic axial load," Composite Structures, vol. 149, pp. 369-384, 2016.

[16] J. C. Zhang, W. Y. Xu, H. L. Wang, R. B. Wang, Q. X. Meng, and S. W. Du, "A coupled elastoplastic damage model for brittle rocks and its application in modelling underground excavation," International Journal of Rock Mechanics and Mining Sciences, vol. 84, pp. 130-141, 2016.

[17] D. Grgic, "Constitutive modelling of the elastic-plastic, viscoplastic and damage behaviour of hard porous rocks within the unified theory of inelastic flow," Acta Geotechnica, vol. 11, no. 48, pp. 95-126, 2016.

[18] X. Yuan, H. Liu, and Z. Wang, "Study on meso-damage and plasticity of rock under compression load," Chinese Journal of Computational Mechanics, vol. 30, no. 1, pp. 149-155, 2013.

[19] X. Yuan, H. Liu, and Z. Wang, "Research on elastoplastic damage constitutive model of rock based on Drucker-Prager criterion," Rock and Soil Mechanics, vol. 33, no. 4, pp. 1103-1108, 2012.

[20] N. Erarslan and D. J. Williams, "Experimental, numerical and analytical studies on tensile strength of rocks," International 
Journal of Rock Mechanics and Mining Sciences, vol. 49, no. 1, pp. 21-30, 2012.

[21] J. Liu, P. Cao, and D. Han, "The influence of confining stress on optimum spacing of TBM cutters for cutting granite," International Journal of Rock Mechanics and Mining Sciences, vol. 88, pp. 165-174, 2016.

[22] X. Liu, J. Liu, and H. Feng, "Experimental study on unloading mechanical properties of sandstone under different initial unloading levels and water pressure," Chinese Journal of Geotechnical Engineering, vol. 40, no. 6, pp. 1143-1151, 2018.

[23] H. Deng, Z. Wang, J. Li, and Q. Jiang, "Research on the influence of unloading rate and pore water pressure on the unloading characteristics of sandstone," Chinese Journal of Geotechnical Engineering, vol. 39, no. 11, pp. 1976-1983, 2017.

[24] Q. Wu, X. Li, and F. Zhao, "Research on failure characteristics of limestone tunnel specimens under pressure relief conditions," Chinese Journal of Rock Mechanics and Engineering, vol. 36, no. 6, pp. 1424-1433, 2017.

[25] W. Chen, S. Lu, X. Guo, and C. Qiao, "Unloading confining pressure for brittle rock and mechanism of rock burst," Chinese Journal of Geotechnical Engineering, vol. 32, no. 6, pp. 963-969, 2010. 